\title{
Temperature-Responsive Nanofibrillar Hydrogels for Cell Encapsulation
}

Héloïse Thérien-Aubin, Yihe Wang, Katja Nothdurft, Elisabeth Prince, Sangho Cho,

\author{
Eugenia Kumacheva
}

\section{Characterization of cellulose nanocrystals}

The cellulose nanocrystals (CNCs) were obtained by acid hydrolysis of wood pulp and supplied by the USDA Forest Product Laboratory. The dimensions of the CNCs was characterized by analyzing by transmission electron microscopy (TEM) and scanning transmission electron microscopy (STEM) images of CNCs (Figure S1).
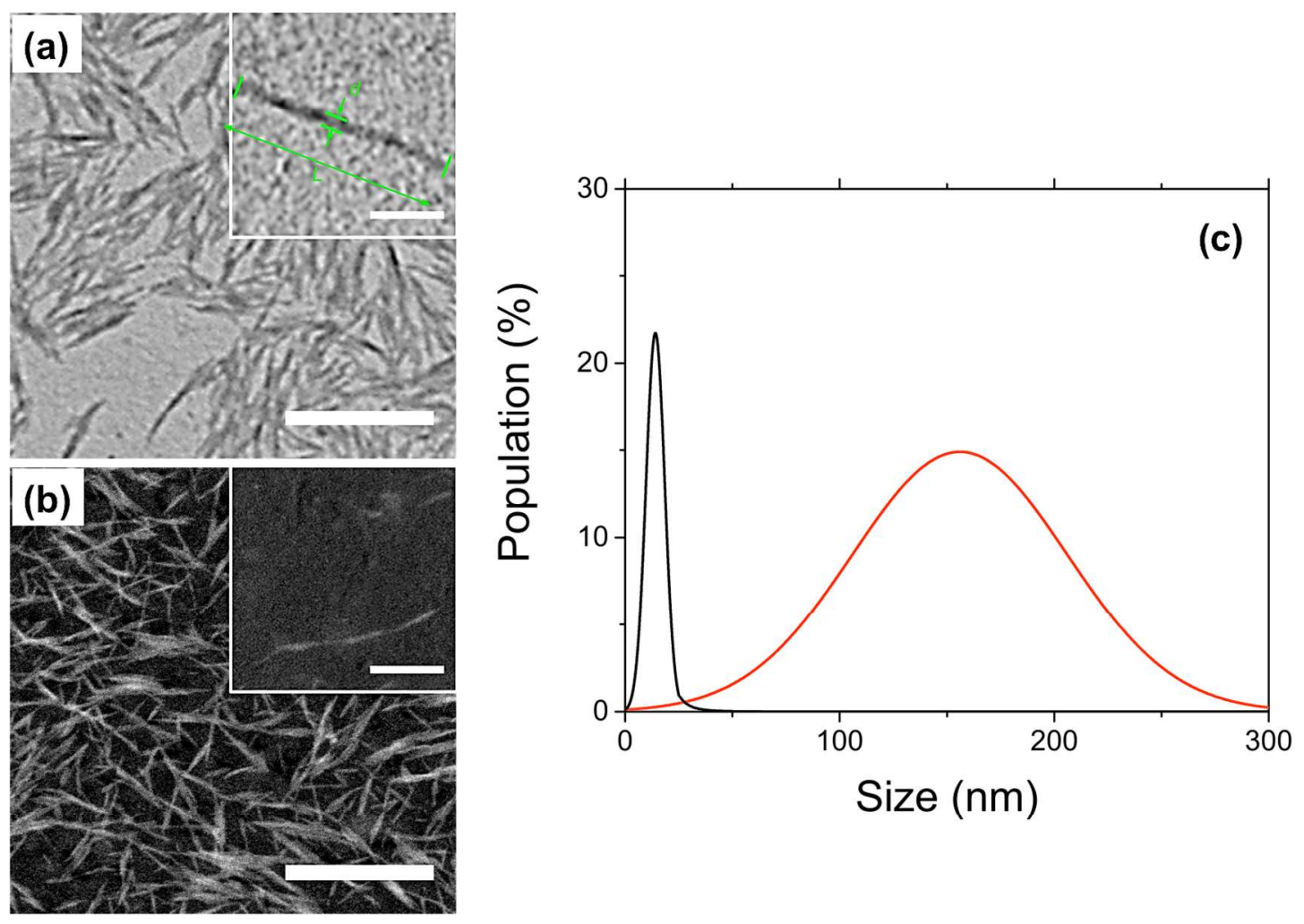
Figure S1. Electron microscopy analysis of CNCs dimensions. (a) TEM image and (b) STEM image of CNCs deposited on the grid from their $0.01 \mathrm{wt} \%$ suspension. The scale bars are 500 $\mathrm{nm}$. The scale bars in insets are $100 \mathrm{~nm}$. (c) Size distribution of the diameter (black) and length (red) of the $\mathrm{CNCs}$, determined by analyzing $250 \mathrm{CNCs}$.

\section{Surface modification of CNC using RAFT polymerization}

Table S1 shows the recipes used for the synthesis of copolymer molecules on the CNC surface. The comonomers, NIPAM and DMAEMA, were mixed with $1 \mathrm{~g}$ of CNC-g-CTA in DMF in a Schlenk flask. Unless otherwise specified, the CNC-g-CTAs with a medium grafting density were used (Table S2). The solid content (the comonomers $+\mathrm{CNCs}$ ) in the suspension was 20 $\mathrm{wt} \%$. To the mixture of CNCs and the comonomers in DMF, $2.2 \mathrm{mg}$ of AIBN was added and the system was purged by 5 freeze-pump-thaw cycles. After that, the solution was immersed for $72 \mathrm{~h}$ in an oil bath at $70{ }^{\circ} \mathrm{C}$.

Table S1. Recipes used for the surface modification of CNCs

\begin{tabular}{cccccc}
\hline Sample name & $\begin{array}{c}\text { CNC-g- } \\
\text { CTA }(\mathbf{g})\end{array}$ & $\begin{array}{ccc}\text { Comonomers } \\
(\mathbf{g})\end{array}$ & NIPAM & DMAEMA & AIBN \\
\hline $\operatorname{mCNC}(50,4)$ & 1.000 & 1.000 & 0.945 & 0.055 & $(\mathbf{g})$ \\
$\operatorname{mCNC}(75,4)$ & 1.000 & 3.000 & 2.835 & 0.165 & 2.2 \\
$\operatorname{mCNC}(85,4)$ & 1.000 & 5.667 & 5.357 & 0.310 & 2.2 \\
$\operatorname{mCNC}(95,4)$ & 1.000 & 19.00 & 17.96 & 1.04 & 2.2 \\
$\operatorname{mCNC}(85,10)$ & 1.000 & 5.667 & 4.909 & 0.758 & 2.2 \\
$\operatorname{mCNC}(85,5)$ & 1.000 & 5.667 & 5.281 & 0.386 & 2.2
\end{tabular}


$\operatorname{mCNC}(85,0)$

\section{Characterization of CNC-g-CTAs}

The grafting density of the polymer chains was controlled by varying the amount of chain transfer agent (CTA) during the esterification of the CNCs. The amount of CTA grafted to the CNCs was characterized by measuring the weight fraction of sulfur in the CNC-g-CTAs by inductively coupled plasma atomic emission spectroscopy (ICP-AEOS) (Optima 7300, PerkinElmer). The results of the determination of grafting density are summarized in Table S2.

Table S2. Grafting density of CNC-g-CTA

\begin{tabular}{|c|c|c|c|c|}
\hline Sample & $\begin{array}{c}\text { Sulfur } \\
\text { content } \\
(w t \%)\end{array}$ & $\begin{array}{c}\text { Feed } \\
\text { CTA/CNC } \\
\text { ratio } \\
\text { (g/g) }\end{array}$ & $\begin{array}{c}\text { Experimental } \\
\text { CTA/ CNC } \\
\text { ratio } \\
(g / g)\end{array}$ & $\begin{array}{l}\text { Grafting density* } \\
\left(\text { CTA } / \mathbf{n m}^{2}\right)\end{array}$ \\
\hline CNCs & $0.94 \pm 0.1$ & -- & -- & -- \\
\hline $\begin{array}{l}\text { Low grafting } \\
\text { density }\end{array}$ & $0.96 \pm 0.04$ & 0.0017 & $0.0007 \pm 0.001$ & $0.006 \pm 0.01$ \\
\hline $\begin{array}{l}\text { Medium } \\
\text { grafting } \\
\text { density }\end{array}$ & $1.2 \pm 0.1$ & 0.0167 & $0.011 \pm 0.005$ & $0.09 \pm 0.04$ \\
\hline $\begin{array}{l}\text { High grafting } \\
\text { density }\end{array}$ & $2.16 \pm 0.03$ & 0.1667 & $0.056 \pm 0.001$ & $0.46 \pm 0.01$ \\
\hline
\end{tabular}

\section{Characterization of mCNCs}

The apparent hydrodynamic diameter of the mCNCs was determined using dynamic light 
scattering. After CNC surface modification with the copolymer molecules, an increase in the apparent diameter of the $\mathrm{CNC}$ was observed (Figure S2).

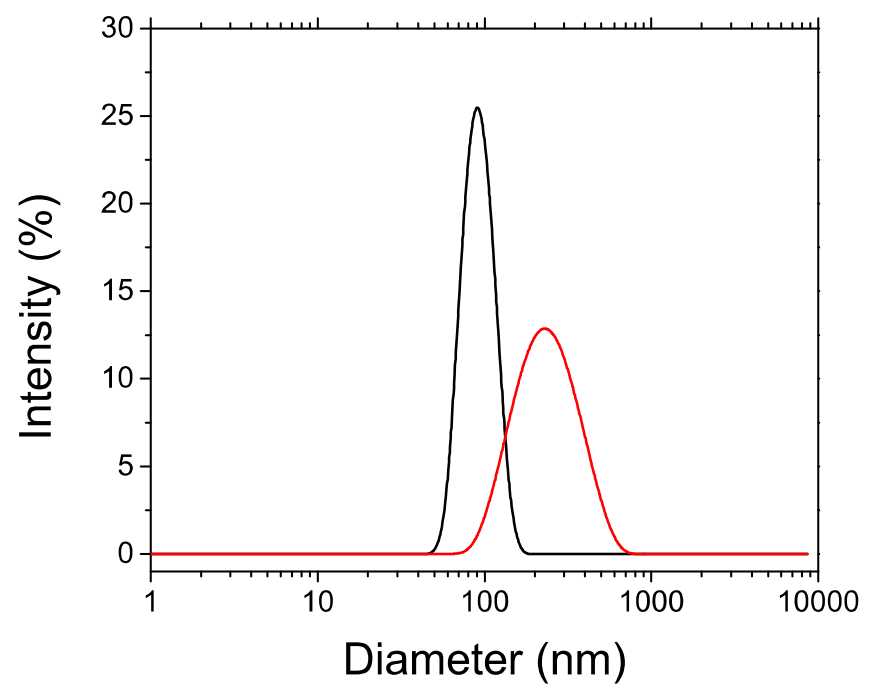

Figure S2. Apparent diameter of non-modified CNCs (black profile) and $\mathrm{mCNCs}(95,4)$ (red profile)

Infrared spectra of the CNCs were recorded after each step of CNC surface modification. Figure S3 shows the spectra of non-functionalized CNCs, CNC-g-CTAs and mCNCs. After the esterification of the CNCs, a small peak at $1650 \mathrm{~cm}^{-1}$ appeared, which was ascribed to the stretching bend of the carbonyl group present in the ester linkage between the $\mathrm{CNC}$ and the CTA. After copolymerization, the spectrum of $\mathrm{mCNC}$ displayed a more complex carbonyl region, due to the carbonyl groups present in the NIPAM and DMAEMA comonomers. 


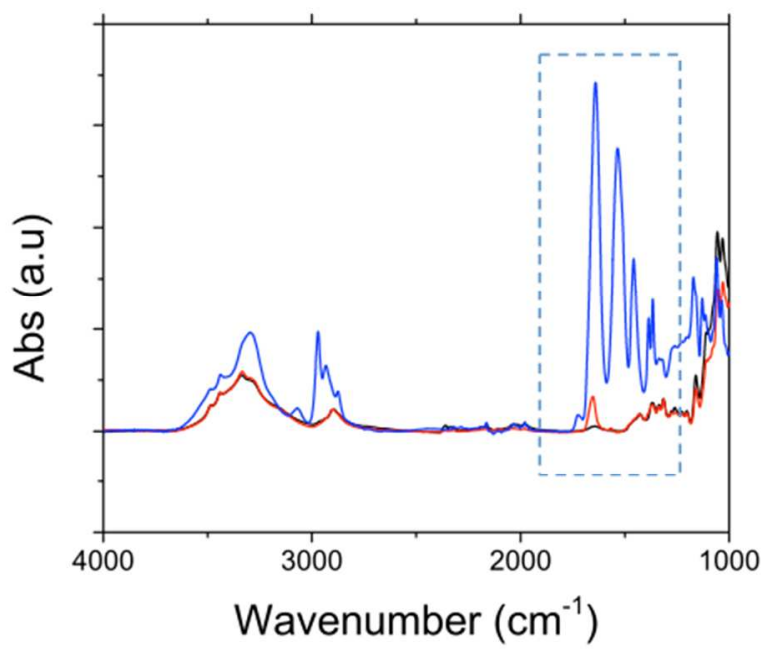

Figure S3. Infrared spectra of pristine CNCs (black spectrum), CNC-g-CTAs (red spectrum) and $\operatorname{mCNCs}(85,4)$ (blue spectrum).

The composition of the copolymer grafted to mCNCs was determined by ${ }^{1} \mathrm{H}$ NMR. The fraction of DMAEMA in the copolymer chains was analyzed by comparing the ratio of the area of the peaks at $4.1 \mathrm{ppm}$ (corresponding to $\mathrm{CH}_{2}$ group next to the ester group in DMAEMA) and $3.9 \mathrm{ppm}$ (corresponding to the $\mathrm{CH}$ from the isopropyl group of the NIPAM). The average degree of polymerization (DP) of the copolymer grafts was obtained by end-group analysis by comparing the area of the peaks (4.1 and $3.9 \mathrm{ppm})$ corresponding to the comonomers and the area of the peak of the CTA at $3.15 \mathrm{ppm}$ (Figure S4). The experimental values of DP and the experimental molar fraction of DMAEMA were used to calculate the number average molecular weight $\left(M_{n}\right)$. The results are shown in Table S3.

For selected mCNC samples, we calculated the theoretical molecular weight, based on the conversion of the comonomers. In order to calculate the conversion of the comonomers, anisole (10 mol\% of the molar concentration of NIPAM) was added to the reaction mixture as an 
internal standard. ${ }^{1} \mathrm{H}$ NMR spectra were obtained for the reaction mixture before and after polymerization. The decrease in the area of the peak at $5.52 \mathrm{ppm}$ (corresponding to the vinyl proton in cis position to the amide substituent in NIPAM) was calculated relative to the area of the peak at $7.26 \mathrm{ppm}$ (corresponding to the phenyl group in anisole) to determine conversion of NIPAM. The decrease in the area of the peak at $6.06 \mathrm{ppm}$ (corresponding to the vinyl proton in DMAEMA) was calculated relative to the area of the peak at $7.26 \mathrm{ppm}$ (corresponding to the phenyl group in anisole) to determine conversion of DMAEMA. The conversion of the comonomers was then used to calculate the theoretical DP, the theoretical molar fraction of DMAEMA, and the theoretical number average molecular weight $\left(\mathrm{M}_{\mathrm{n}, \mathrm{th}}\right)$. The results are shown in Table S4. The theoretical results agreed with the experimental results in Table S3.

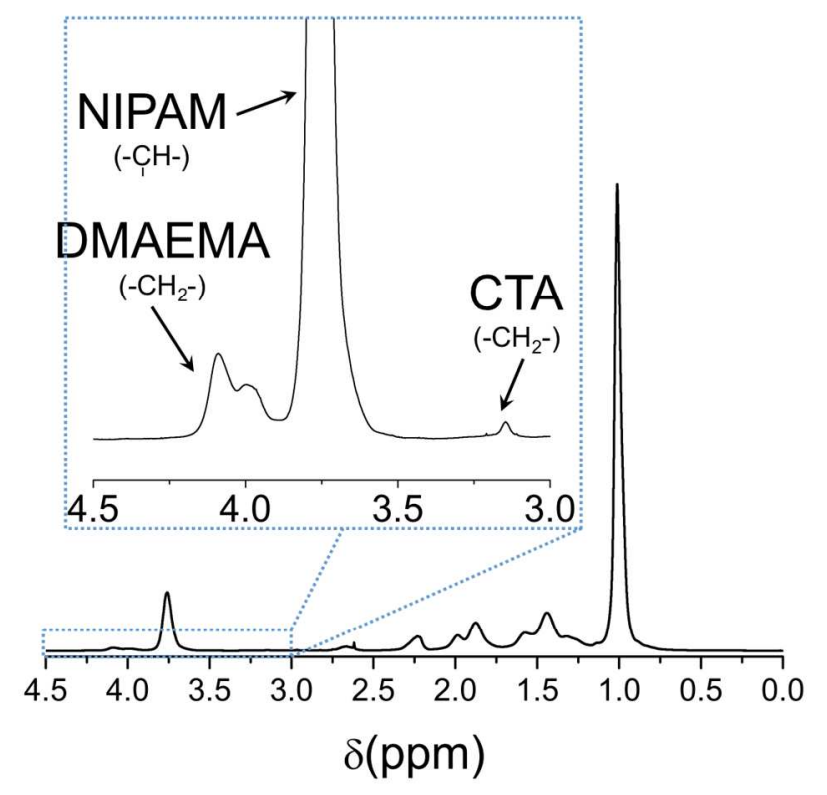

Figure S4. NMR spectra of mCNCs $(50,4)$ 
Table S3. Characterization of mCNCs

\begin{tabular}{cccccc}
\hline $\begin{array}{c}\text { Modified } \\
\text { CNC }\end{array}$ & $\begin{array}{c}\text { Target } \\
\text { DP }\end{array}$ & $\begin{array}{c}\text { Experimental } \\
\text { DP }\end{array}$ & $\begin{array}{c}\text { DMAEMA } \\
\text { content in } \\
\text { the feed } \\
\text { mixture } \\
\text { (mol\%) }\end{array}$ & $\begin{array}{c}\text { DMAEMA } \\
\text { content in } \\
\text { the } \\
\text { copolymer } \\
\text { (mol\%) }\end{array}$ & $\begin{array}{c}\text { Experimental } \\
\text { (kDa) }\end{array}$ \\
\hline $\operatorname{mCNC}(50,4)$ & 319 & $330 \pm 20$ & 4 & $4.4 \pm 0.1$ & $39 \pm 3$ \\
$\operatorname{mCNC}(75,4)$ & 958 & $960 \pm 50$ & 4 & $3.9 \pm 0.2$ & $110 \pm 10$ \\
$\operatorname{mCNC}(85,4)$ & 1810 & $1900 \pm 100$ & 4 & $3.5 \pm 0.2$ & $220 \pm 20$ \\
$\operatorname{mCNC}(95,4)$ & 6067 & $6400 \pm 200$ & 4 & $3.4 \pm 0.4$ & $700 \pm 100$ \\
$\operatorname{mCNC}(85,10)$ & 1769 & $1800 \pm 100$ & 10 & $8.9 \pm 0.3$ & $210 \pm 20$ \\
$\operatorname{mCNC}(85,5)$ & 1803 & $2000 \pm 100$ & 5 & $5.2 \pm 0.2$ & $230 \pm 20$ \\
$\operatorname{mCNC}(85,0)$ & 1838 & $1900 \pm 100$ & 0 & 0 & $210 \pm 10$ \\
\hline
\end{tabular}

Table S4. Characterization of mCNCs: theoretical comonomer conversion.

\begin{tabular}{ccccccc}
\hline $\begin{array}{c}\text { Modified } \\
\mathbf{C N C}\end{array}$ & $\begin{array}{c}\text { Target } \\
\mathbf{D P}\end{array}$ & $\begin{array}{c}\text { Conversion } \\
\text { of NIPAM } \\
\mathbf{( \% )}\end{array}$ & $\begin{array}{c}\text { Conversion } \\
\text { of } \\
\text { DMAEMA } \\
\mathbf{( \% )}\end{array}$ & $\begin{array}{c}\text { Theoretical } \\
\mathbf{D P}\end{array}$ & $\begin{array}{c}\text { DMAEMA } \\
\text { content in } \\
\text { the } \\
\mathbf{c o p o l y m e r} \\
\mathbf{( m o l \% )}\end{array}$ & $\begin{array}{c}\text { Theoretical } \\
\mathbf{M}_{\mathbf{n}, \text { th }} \\
(\mathbf{k D a})\end{array}$ \\
\hline $\operatorname{mCNC}(85,4)$ & 1810 & 94.7 & 100 & 1717 & 4.2 & 198 \\
$\operatorname{mCNC}(95,4)$ & 6067 & 90.7 & 100 & 5525 & 4.4 & 636 \\
$\operatorname{mCNC}(85,10)$ & 1769 & 80.8 & 100 & 1463 & 12.1 & 173 \\
$\operatorname{mCNC}(85,0)$ & 1838 & 96.6 & 0 & 1775 & 0 & 201 \\
\hline
\end{tabular}




\section{Aggregation of $\mathrm{mCNC}$ in dilute suspensions}

The apparent hydrodynamic diameter of the mCNCs in dilute suspension was determined in dynamic light scattering experiments in the temperature range from 20 to $60{ }^{\circ} \mathrm{C}$ (Figure S5). Below the lower critical aggregation temperature (LCAT), the mCNCs were well-dispersed, however upon heating, in the temperature range between 33 and $43{ }^{\circ} \mathrm{C}$, their size increased due to the formation of aggregates. The size of $\mathrm{mCNC}$ aggregates increased with time. Upon reduction in temperature in the range from 35 to $30^{\circ} \mathrm{C}$, the size of mCNCs increased due to aggregate dissociation.

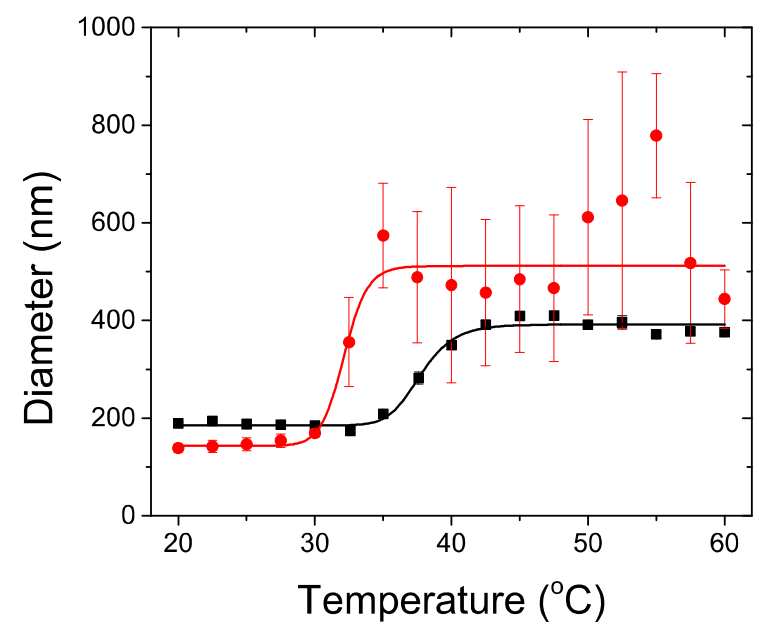

Figure S5. Variation in the apparent diameter of $\operatorname{mCNC}(85,4)$ in water upon heating (black line) and cooling (red line). The lines are given for eye guidance. The concentration of mCNCs in the suspension was $0.01 \mathrm{wt} \%$.

The value of LCAT decreased when the liquid medium was changed from deionized water to the buffer (HBSS) and then, to the cell culture medium. Figure S6 shows that the value of LCAT was mainly influenced by the presence of salt in HBSS. No significant difference in the LCAT 
value was observed, when the medium was changed from HBSS to the cell culture medium for either fibroblasts, or $\mathrm{T}$ cells.
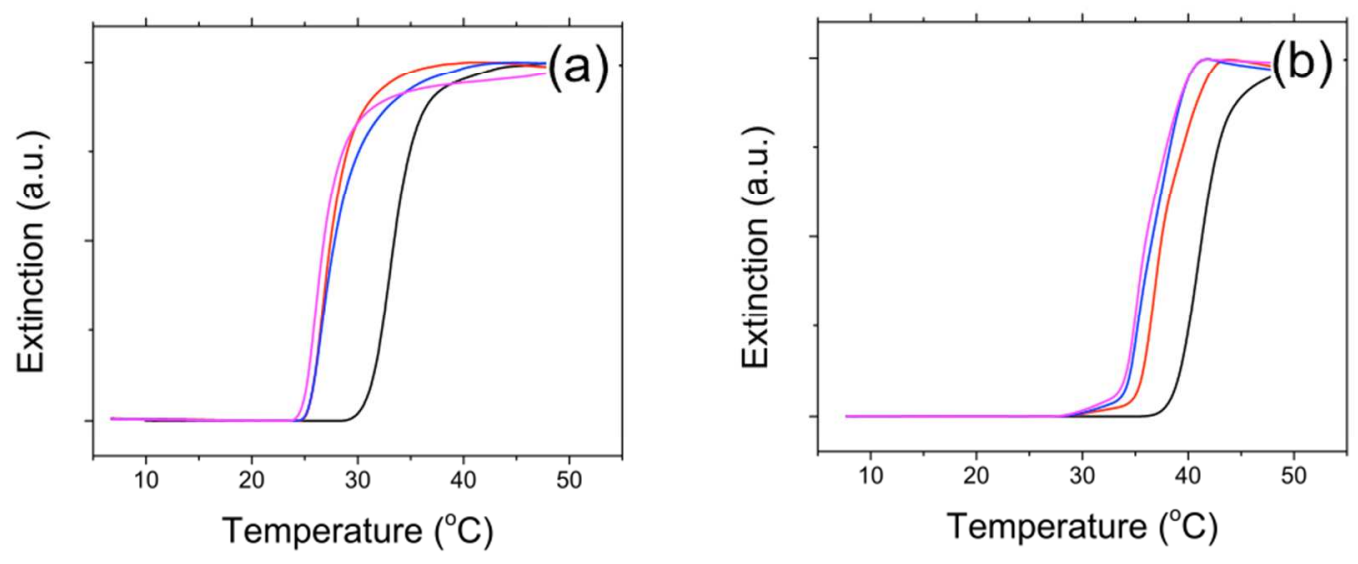

Figure S6. Effect of the medium on the lower critical aggregation temperature (LCAT) of $\operatorname{mCNC}(85,0)$ (a) and $\operatorname{mCNC}(85,4)(b)$, both in $0.1 \mathrm{wt} \%$ suspension in water (black curves), HBSS (red curves), cell culture medium for T-Cells (blue curves) and cell culture medium for fibroblasts (pink curves). The curves are given for eye guidance.

We examined the dependence of LCAT on the composition of the copolymer grafted molecules, the copolymer-to-CNC weight ratio, and the grafting density of the copolymer molecules on the surface of mCNCs. Figure S7 shows that only the composition of the copolymer, that is, the molar concentration of DMAEMA, influenced the value of LCAT. 

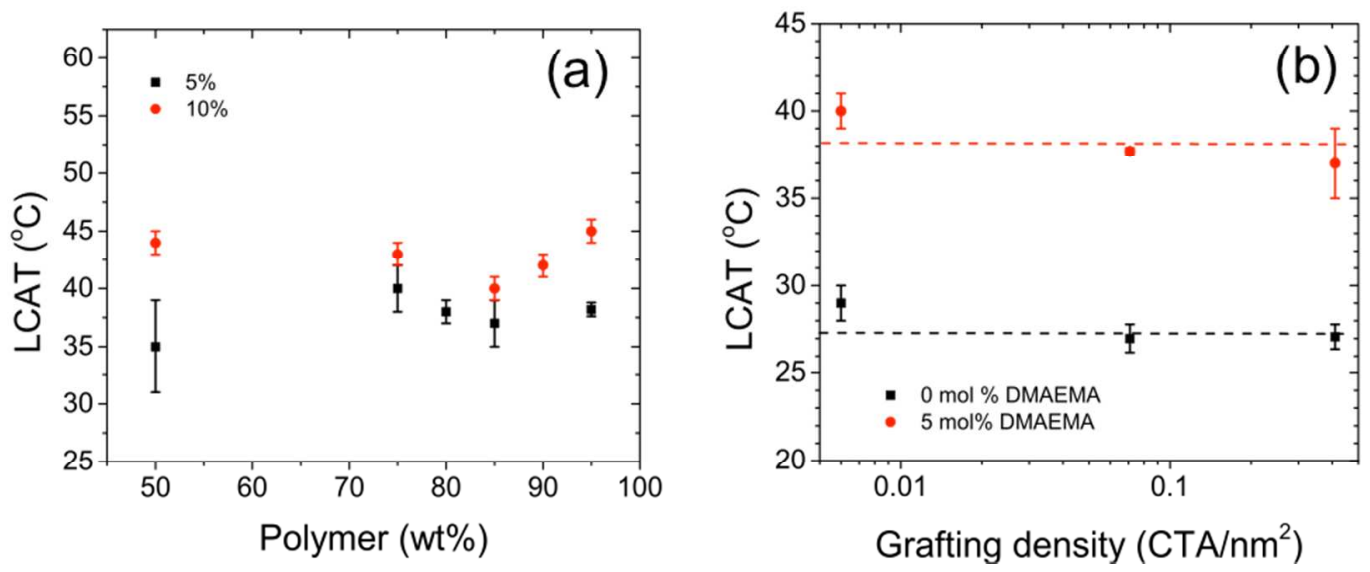

Figure S7. Variation in the lower critical aggregation temperature (LCAT) of mCNCs in 0.1 wt $\%$ suspension in HBSS. (a) Effect of the copolymer-to-CNC ratio at $\mathrm{mCNC}(\mathrm{X}, 5)$ (black) and $\mathrm{mCNC}(\mathrm{X}, 10)$ (red). (b) Effect of the copolymer grafting density for $\mathrm{mCNC}(85,0)$ (black) and $\mathrm{mCNC}(85,5)$ (red). The dashed lines in (b) are given for eye guidance.

\section{Gelation of mCNCs in concentrated suspension.}

The temperature, at which gel formation occurred in the absence and in the presence of cells in an $\mathrm{mCNC}$ suspension, was characterized by measuring extinction of $\mathrm{mCNC}$ suspensions in a 96wells plate using a plate reader. A well plate containing a mixed suspension of mCNCs and either fibroblasts, or $\mathrm{T}$ cells was inserted in the plate reader and extinction was recorded for the temperature range between 25 and $50{ }^{\circ} \mathrm{C}$. In the control experiments, a cell-free mCNC suspension was heated from 25 to $50{ }^{\circ} \mathrm{C}$. Upon gel formation, a sharp increase in extinction occurred, due to increased scattering. Figure S8 shows that the gel formation temperature was not affected by the presence of cells. 


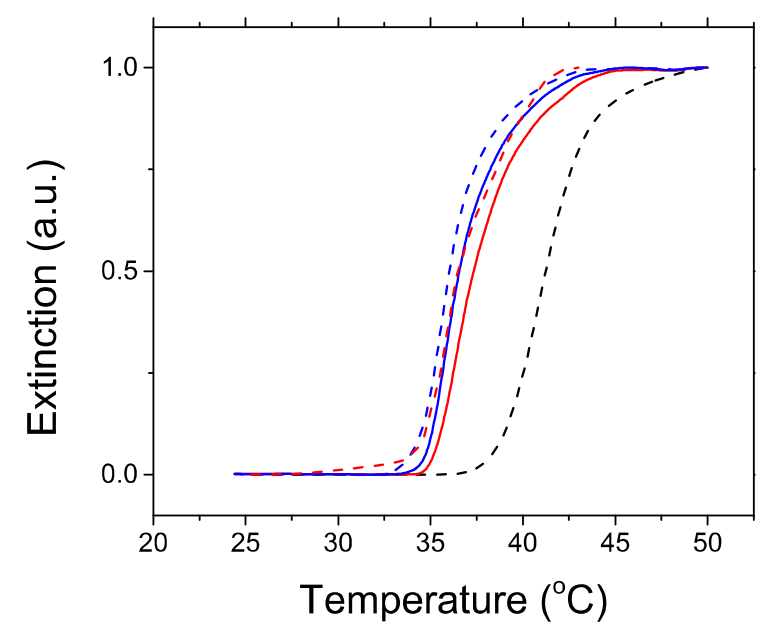

Figure S8. Effect of the addition of cells on gelation of $\operatorname{mCNC}(85,4)$ suspension. Formation of a gel from a $4 \mathrm{wt} \%$ suspension of $\mathrm{mCNC}(85,4)$ in water (dashed black line), in the cell-free cell culture medium for $\mathrm{T}$ cells (red dashed line), in the culture medium for $\mathrm{T}$ cells with 5000 cells/well (red solid line), in the cell-free cell culture medium for fibroblasts (blue dashed line) and in the cell-free cell culture medium for fibroblasts with 5000 cells/well (blue solid line). The lines are given for eye guidance.

\section{Rheology of mCNC gel}

To explore the role of surface modification of CNCs with copolymer grafts, the rheological properties of the hydrogels formed by nonmodified CNCs and poly(NIPAm-co-DMAEMA) copolymer were examined at 25 and $37{ }^{\circ} \mathrm{C}$. Figure S9 shows that the hydrogels formed by nonmodified CNCs from their $4 \mathrm{wt} \%$ suspension in water did not display a thermoresponsive behavior, while a sol-gel transition was observed for the solution of poly(NIPAM-coDMAEMA). 

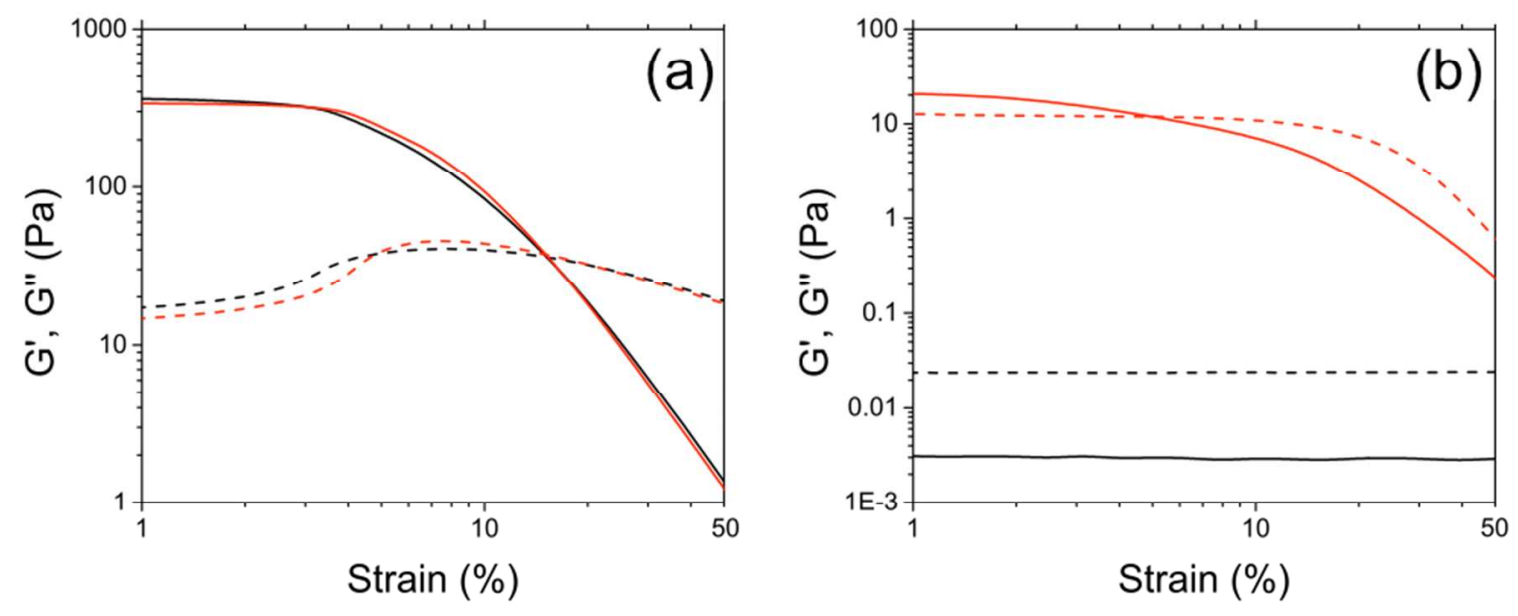

Figure S9. Strain-sweep experiments conducted with a hydrogel formed from $4 \mathrm{wt} \%$ suspension of non-modified CNCs (a) and $4 \mathrm{wt} \%$ of poly(NIPAM-co-DMAEMA) at $25{ }^{\circ} \mathrm{C}$ (black curves) and $37^{\circ} \mathrm{C}$ (red curves). Lines are shown for eye guidance, G' (solid line) and G" (dashed line).

Figure S10 show the results of the frequency sweep experiment performed for the $\mathrm{mCNC}$ gel above LCAT and mCNC suspension below LCAT.

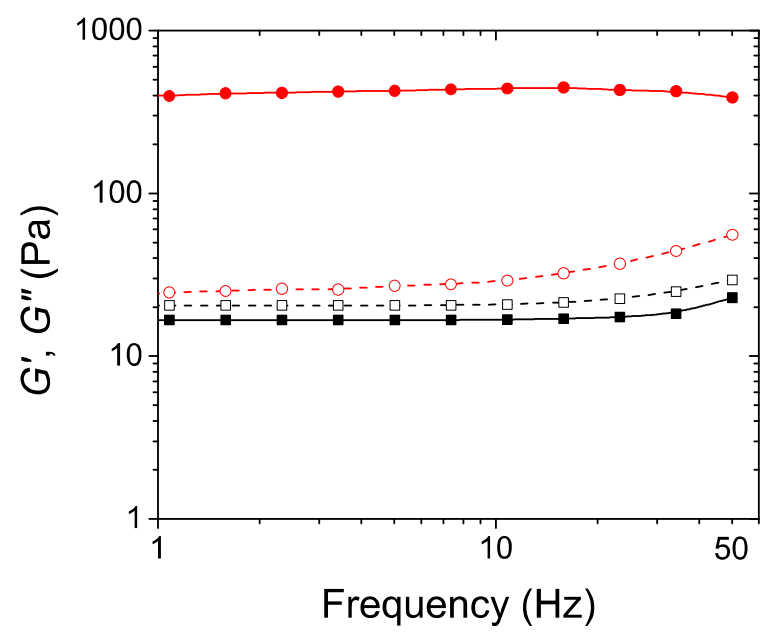

Figure S10. Frequency-sweep experiments conducted with a hydrogel formed from $4 \mathrm{wt} \%$ suspension of $\mathrm{mCNC}(85,4)$ at $25{ }^{\circ} \mathrm{C}$ (black lines) and $37{ }^{\circ} \mathrm{C}$ (red lines). Lines are shown for eye guidance, $\mathrm{G}^{\prime}$ (solid lines) and $\mathrm{G}^{\prime \prime}$ (dashed lines). 


\section{Structure of hydrogels}

The structure of the frozen and dried mCNC hydrogels was analyzed by scanning electron microscopy (SEM). Figure S11 shows representative low-magnification images of the mCNC hydrogels prepared from aqueous suspensions with different $\mathrm{mCNC}$ concentration at varying copolymer concentration.
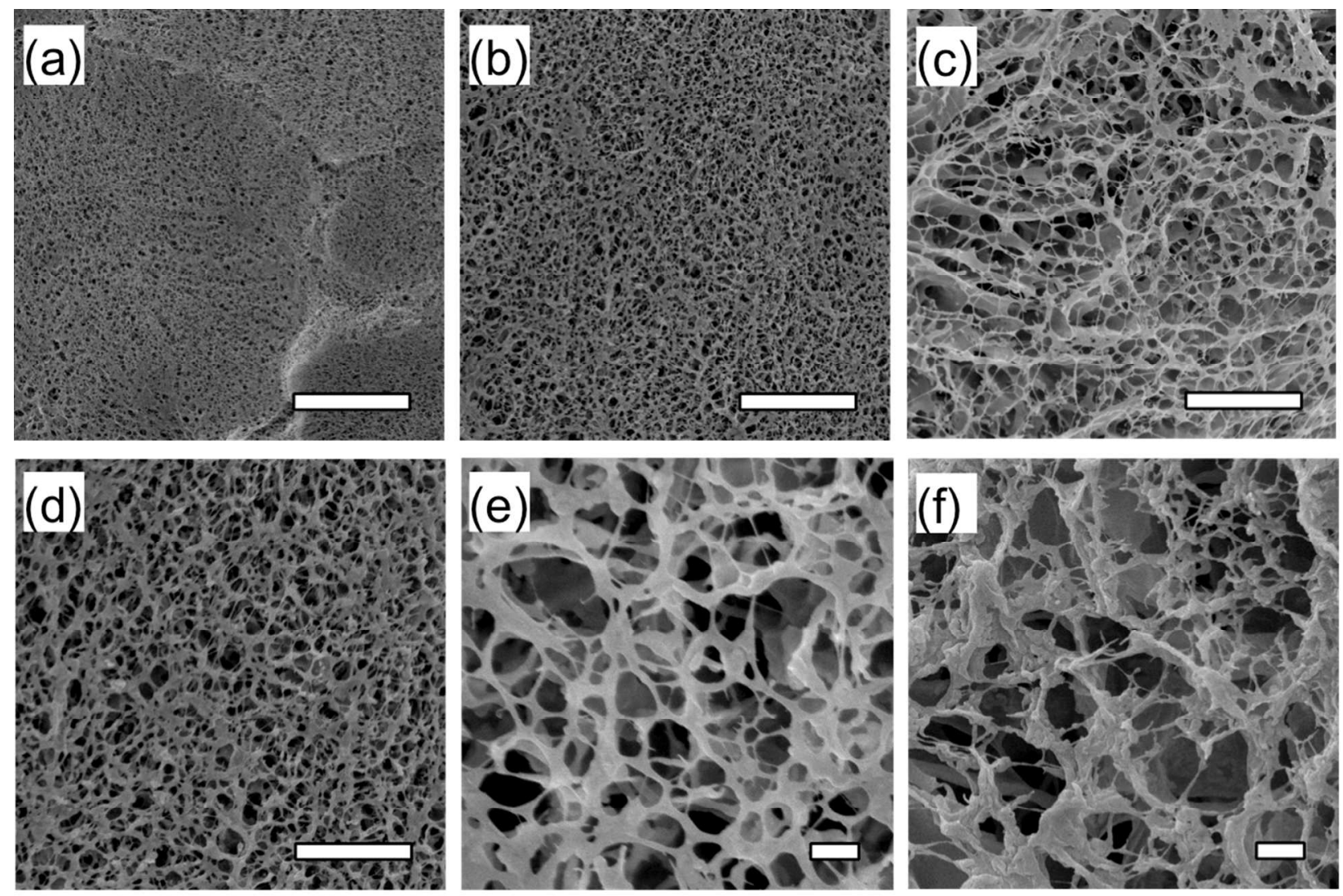

Figure S11. (a-c) Low-magnification SEM images of hydrogels formed from $4 \mathrm{wt} \%$ $\operatorname{mCNC}(75,4)(a), \operatorname{mCNC}(85,4)(b)$, and $\operatorname{mCNC}(95,4)(c)$ suspensions. Scale bars in a-c are 10 $\mu \mathrm{m}$. (d) SEM image of hydrogels formed from $4 \mathrm{wt} \% \mathrm{mCNC}(85,4)$ suspension. The scale bar is $5 \mu \mathrm{m}$. (e-f) High magnification SEM images of hydrogels formed from $4 \mathrm{wt} \%$ (e) and $3 \mathrm{wt} \%$ (f) suspensions of $\mathrm{mCNC}(85,4)$. The scale bars in e-f are $1 \mu \mathrm{m}$.

The effect of the temperature of the sample preparation before the rapid freezing of the structure was realized for samples casted above and below the LCAT (Figure S12). 

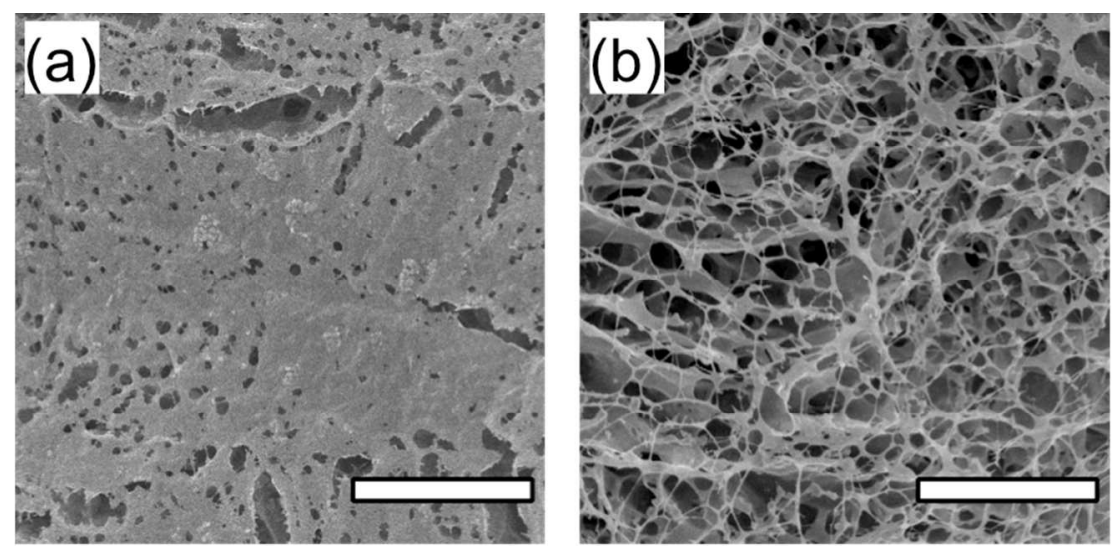

Figure S12. SEM images of $\operatorname{mCNC}(95,4)$ samples prepared by rapid freezing of a $4 \mathrm{wt} \%$ suspension of mCNCs at (a) $25^{\circ} \mathrm{C}$ and (b) $40{ }^{\circ} \mathrm{C}$. Scale bars are $10 \mu \mathrm{m}$.

\section{Light scattering by the $\mathrm{mCNC}$ hydrogel before and after cell release}

After cell culture experiments were complete, the cells were released from the $\mathrm{mCNC}$ hydrogels. Figure S13 shows transmission bright field microscopy images of the cells before and after release from the hydrogels.
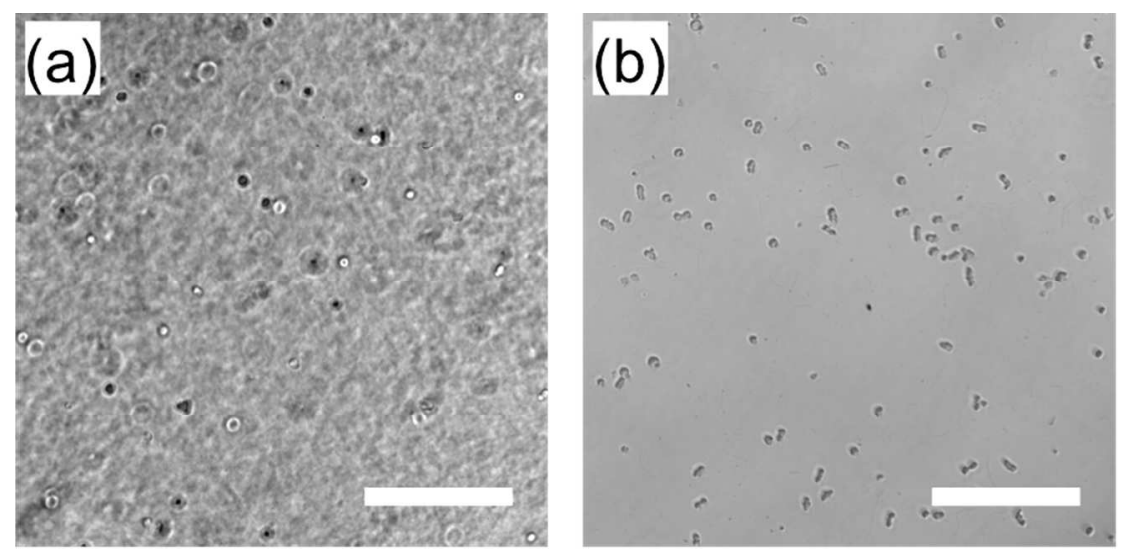

Figure S13. Transmission bright field microscopy images of the $\mathrm{mCNC}(95,4)$ hydrogel at $37{ }^{\circ} \mathrm{C}$ before cell release (a) and at room temperature after cell release (b). Scale bars are $250 \mu \mathrm{m}$. 


\section{Live/dead staining of fibroblasts and $T$ cells before and after releasing from $\mathrm{mCNC}$ gels}

The cells cultured in the mCNC hydrogels were released from the gel and analyzed by fluorescence microscopy to explore the advantages of the thermoreversible $\mathrm{mCNC}$ hydrogels for the characterization of cells cultured in nanofibrillar gels (Figure S14 and S15).
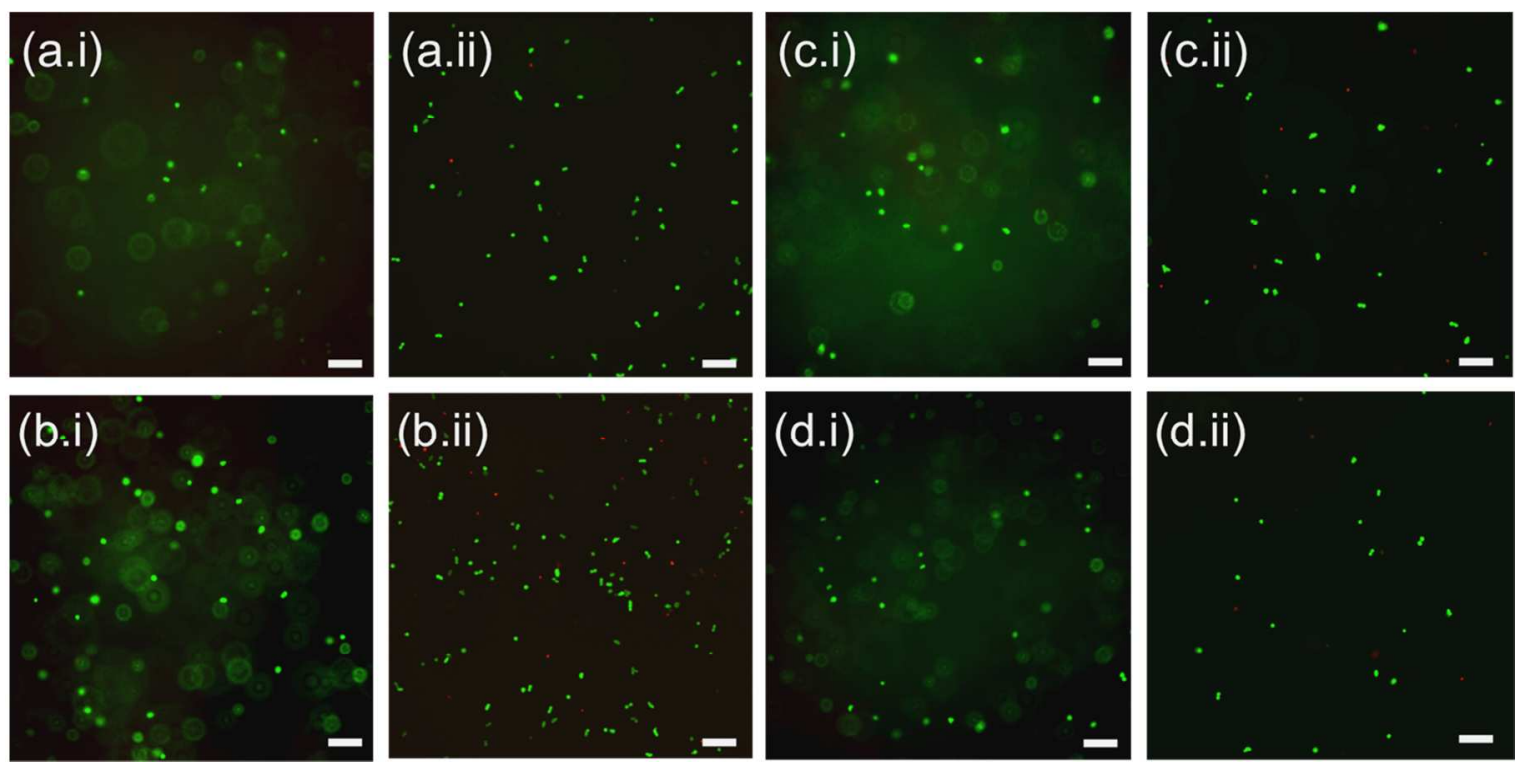

Figure S14. Live/dead assay of fibroblasts after $24 \mathrm{~h}$ culture in $3 \mathrm{wt} \%$ (a) and $4 \mathrm{wt} \%$ (b) mCNC $(95,4)$ hydrogel and in $3 \mathrm{wt} \%$ (c) and $4 \mathrm{wt} \%$ (d) $\mathrm{mCNC}(85,4)$ hydrogel before (i) and after (ii) disintegration of the nanofibrillar network. The live fibroblasts were stained with Calcein AM (green) and the dead fibroblasts were stained with Ethidium Homodimer I (red). Scale bars are $100 \mu \mathrm{m}$. 

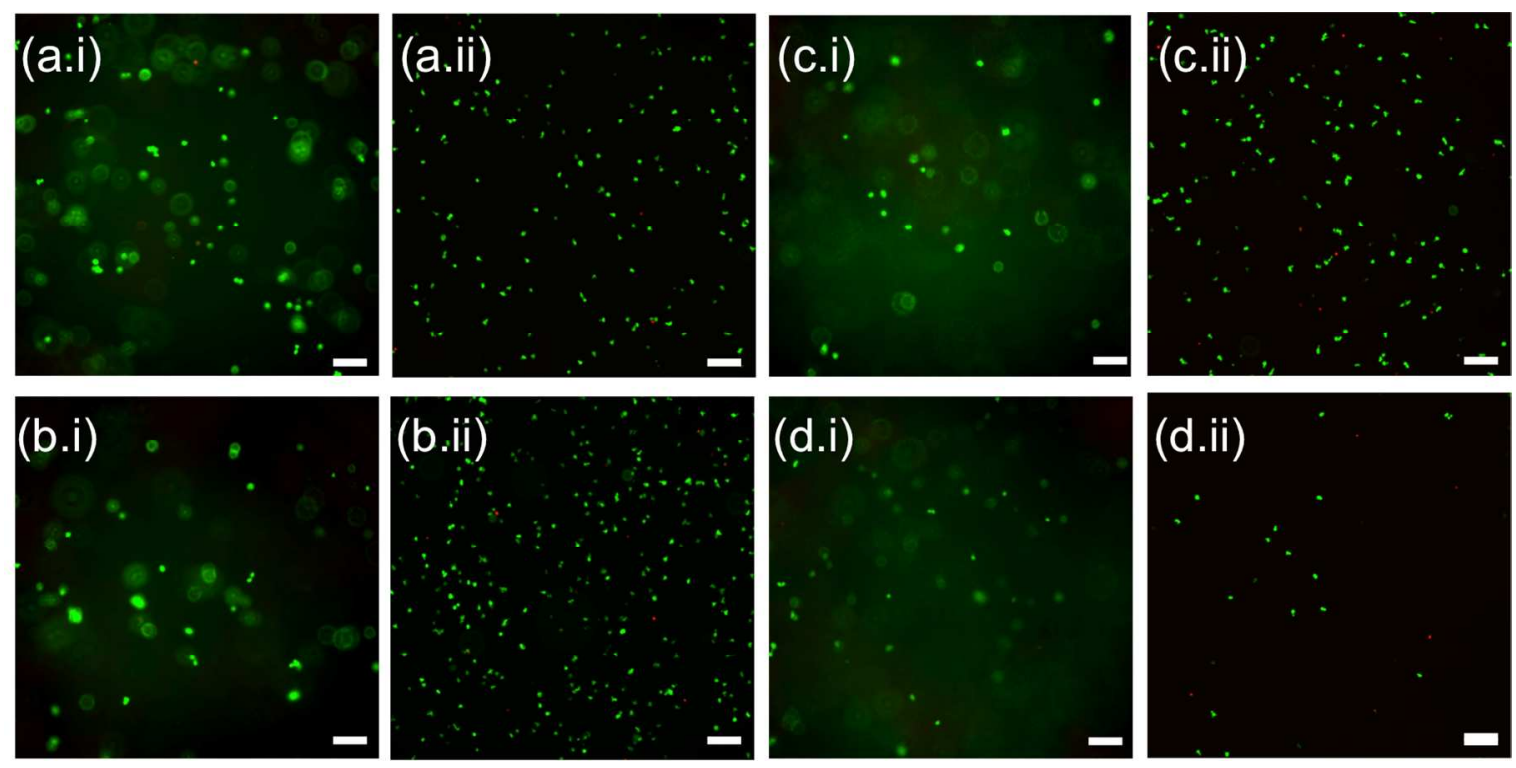

Figure S15. Live/dead assay of $\mathrm{T}$ cells after $24 \mathrm{~h}$ of culture in $3 \mathrm{wt} \%$ (a) and $4 \mathrm{wt} \%$ (b) mCNC $(95,4)$ hydrogel and in $3 \mathrm{wt} \%$ (c) and $4 \mathrm{wt} \%$ (d) $\mathrm{mCNC}(85,4)$ hydrogel before (i) and after (ii) disintegration of the nanofibrillar network. The live $\mathrm{T}$ cells were stained by Calcein AM (green) and the dead T cells were stained with Ethidium Homodimer I (red). Scale bars are 100 $\mu \mathrm{m}$.

\section{Cytotoxicity of control systems}

The proliferation of fibroblasts and $\mathrm{T}$ cells was characterized following cell encapsulation in the hydrogels formed by non-modified CNCs and in poly(NIPAM-co-DMAEMA), and compared with cell proliferation in the mCNC hydrogels. Figures S16 and S17 show that the proliferation of $\mathrm{T}$ cells was stronger in the hydrogels formed $\mathrm{mCNCs}$ than in both control systems. The proliferation of fibroblasts was comparable in $\mathrm{mCNC}$ and $\mathrm{CNC}$ hydrogels, and inferior to the copolymer hydrogel. 


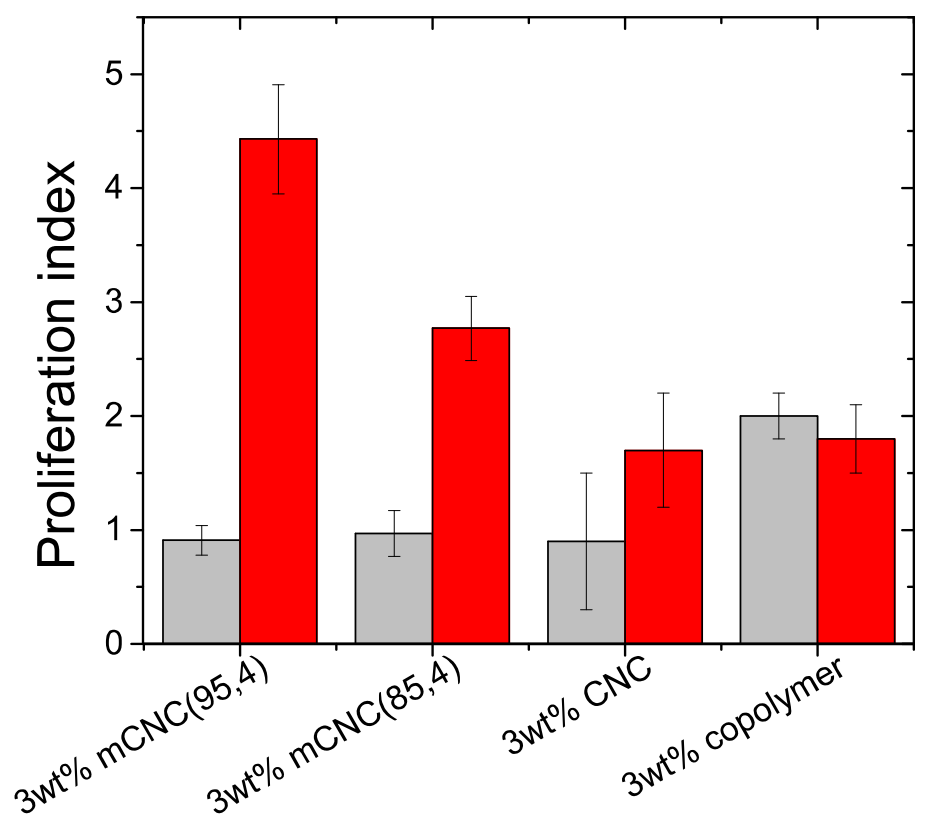

Figure S16. Proliferation index of fibroblasts (gray bars) and T cells (red bars) in different environments after $24 \mathrm{~h}$ of culture at $37^{\circ} \mathrm{C}$.

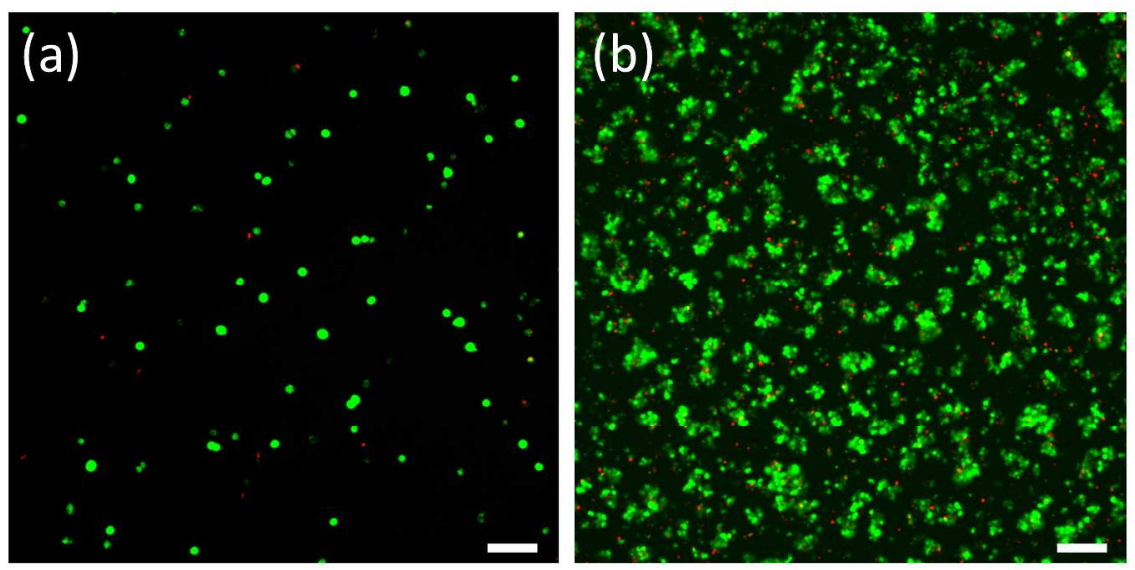

Figure S17. Live/dead assay of fibroblasts (a) and $\mathrm{T}$ cells (b) after 7-day culture in $3 \mathrm{wt} \%$ mCNC $(95,4)$ hydrogel after disintegration of the nanofibrillar network. The live cells were stained by Calcein AM (green) and the dead cells were stained with Ethidium Homodimer I (red). Scale bars are $100 \mu \mathrm{m}$. 